\title{
Tracking Mental Health in Sustainable Development Frameworks in Politically Violent Zones: Need for Framework and Cognizance- Kashmir in Context
}

\author{
Aabid Bhat (Corresponding author) \\ Department of Social Work, Jamia Millia Islamia \\ India \\ E-mail: aabidbhat2012@gmail.com \\ Aadil Farooq \\ Centre for Community Medicine, Jawaharlal Nehru University \\ India \\ E-mail: aadilshah321@gmail.com
}

Received: March 8, 2017 Accepted: March 26, 2017 Published: May 11, 2017

doi:10.5296/ijch.v4i1.10899 URL: https://doi.org/10.5296/ijch.v4i1.10899

\begin{abstract}
As a conceptual framework, Sustainable Development (SD) intends to improve current Well-Being, while preserving or maintaining the basis for future Well-Being (Solow, 1991). In order to measure Sustainable Development various indicators were chosen, among which health has been considered as an important indicator. As a result, we see a huge focus on health in Sustainable Development frameworks. But, the emphasis of frameworks has been only on the physical and epidemiological factors affecting the health. In contrary, in context of a highly political turmoil zone, it is the psychological well-being that is severely affected. This component of health i.e., psychological well being is neglected to find a significant place in Sustainable Development frameworks. Since, these frameworks are crucial for national level policy making and it is likely that policies formulated on such frameworks may not replicate the same successful results in every context (such as in Armed Conflict). With such understanding in the background, this paper will show the need to focus on mental health in armed conflict situations in Sustainable Development frameworks. This paper will
\end{abstract}


attempt to show how ignoring mental health in armed conflict situations impede development. The need to develop a holistic framework which focuses on mental health in Armed Conflict situations will be highlighted in context of Kashmir.

Keywords: Armed conflict, Sustainable development frameworks, Psychological well-being, Development, Mental health, Kashmir

\section{Understanding Sustainable Development}

The earlier conception of development was to increase the growth or to increase the GDP. This conception was more economic in its nature. The resources were exploited infinitely to increase the output. No consideration was being paid whether it affects environment negatively. The conventional form of development and Western Developmental Model was propagated. This model believed in "instrumental value" of nature while neglecting its "intrinsic value". This model prioritized the economic growth and assumed consumption as important contributor to human welfare. The "Standard of Living" was considered as an indicator of development. Soon after the $19^{\text {th }}$ century this conception was changed, when focus was laid on "Quality of Life" as a determinant of development. Till now, growth was considered as an end in itself. But with the beginning of social science and humanistic discourse it was emphasized that this notion of development cannot suffice. The "Means" through which this growth was attained was questioned. Paradigm shift is seen in development discourse posing the question of -"Development for Whom? By What Means? At What Cost? It was felt that development as an increase in growth cannot sustain alone, but need to have a certain prefix for its sustenance, hence the Sustainable Development.

Sustainability means "to sustain, to maintain, and to continue". Sustainable Development requires mandatorily a human effort to perpetuate the pace of development. To put simply, humans are agents of Sustainable Development. Without taking the human society into consideration, the development discourse is incomplete and likely to fail at any course of time.

Sustainable Development encompasses in it three main dimensions- Economic, Environmental, and Social [See fig 1].

It delineates that the main objective of Sustainable Development is to: a) Protect and Safeguard Environment, b) Maintain Stable Level of Economic Growth, c) and Social Progress that recognizes the needs of everyone ${ }^{1}$. The concept of Sustainable Development is however very broad and it paves a challenge in understanding what sort of things goes in this overlapped Sustainability Venn diagram in a practical sense. To avoid this confusion various indicators in the form of frameworks are being provided which measure the Sustainable Development.

The "Four Capital Model"2 framework described by Paul Ekins focuses on the Human

\footnotetext{
${ }^{1}$ Parker, Sommer, Uren. (2003). Sustainable Development: Understanding the Concept and Practical Challenge, Engineering Sustainability, 156 issue ESI.

${ }^{2}$ Four Capital Model includes Natural Capital, Human Capital, Social Capital, Manufactured Capital as indicators of Sustainable Development. For further explanation see Parker, Sommer, Uren. (2003). Sustainable
} 
capital $^{3}$ as one of the important component of Sustainable Development. It has been acknowledged that increased focus and investment on human capital has been viewed as most essential ingredient in development strategy ${ }^{4}$. Thus, it can be said that human capital is an indivisible and basic component of Sustainable Development.

Since humans are an important aspect of Sustainable Development, any negative change to their health standards will ultimately affect the Sustainable Development. Therefore a huge focus has been paid on maintaining a good health.

The health of people gets affected by the environment they live in. A pollutant and disease free environment provides healthy conditions for nourishment. Recognizing this relation, Sustainable Development Frameworks indicating the Environmental Indicators were put forward. These frameworks however have focused only on the physical and epidemiological factors affecting the health on exposure to environment. Since the health does not cover only physical aspect but mental aspect as well. In context of politically violent zones it has been established that it is the mental health and psychological well being that debilitates to a considerable extent. This link seems to be gone un-acknowledged in these frameworks.

\section{Analyzing Sustainable Development Frameworks}

Upon looking the various models of Sustainable Development, doubtlessly health receives a fine position as an indicator of development. Various governmental and Non Governmental organizations attempted to develop the indicators measuring Sustainable Development with the support of United Nations. Organizations such as OECD, UNEP/RIVM, World Resource Institute (WRI), World Bank, SCOPE became potentially involved in determining the indicators to monitor environmental trends. This core set of developed indicators serve as a support for Nation Level Decision- Making5. There are about 130 indicators compiled by commission on Sustainable Development. The indicators have been categorized as: Housing and Urban Indicators, Social Indicators and Health Indicators ${ }^{6}$.

Enhanced understanding and linkage among the various chosen indicators in the environment, development processes affecting human health, resulted in various frameworks used by the policy and decision makers. These frameworks form the base of any developmental policy. Various frameworks which have been developed are discussed as:

\section{- Pressure State Response (PSR) Framework- Developed by OECD.}

This framework gives a quick description of interactions between socio-ecological components of environment. This framework focuses on the anthropogenic pressures creating

Development: Understanding the Concept and Practical Challenge, Engineering Sustainability, 156 issue ESI.

3 Human capital encompasses Health, Knowledge, Skills, Motivation, and Spiritual Ease of the People.

${ }^{4}$ Parker, Sommer, Uren. (2003). Sustainable Development: Understanding the Concept and Practical Challenge, Engineering Sustainability, 156 issue ESI.

5 Schirnding. Von. Yasmin. (2002). Health and Environmental Indicators in Context of Sustainable Development, Canadian Journal of Public Health.

6 ibid. 
the environmental disturbance and the response invoked by the stakeholders against the changing state of environment. This model however has been criticized because of its over simplified representation of socio-ecological interactions and structures and the challenge associated with establishing cause- effect relationships.

- Pressure- State- Impact- Response (PSIR) Framework- Developed by European Environmental Agency (EUA, 2003).

This framework is modified version of PSR, in which the impact of hazardous environmental exposure on health has been taken into cognizance.

- DPSEEA- (Driving Forces, Pressures, State, Exposures, Health Effects, and Action) Framework- Developed by WHO.

It is refinement of PSR framework wherein the component of "Driving Forces" referring to factors which motivate and push the environmental processes, has been involved. Population growth, technological development, economic development and policy intervention are being considered as the driving forces, generating the "pressure" on environment. Generally "pressure" is generated by all sort of economic activity. This resulted in all sort of chemical pollutants which are outpoured to land, water and air, changing the "state" (quality) of environment which calls for environmental hazards. The exposure of individual to environmental hazards affects negatively well being and health causing morbidity, sentinel diseases, death in extreme cases. As a response this invokes "actions" among the stakeholders which can be either at individual level or policy level.

The above frameworks articulate a connection among the various factors influencing the health and environment. These indicators form a crucial link in decision making chain ${ }^{7}$. These frameworks have focused only on the physical and epidemiological factors which disturb the health of an individual. On the basis of these indicators the response always focused on technical solution and do not take into account the political dimension of these responses $^{8}$. These frameworks are considered universal. No doubt, decision making along such lines will bring the positive and improved health, but it may not necessarily bring the expected outcomes in every situation (such as in armed conflict situation). These may prove incompatible in particular situations. These frameworks have focused on the "effects" on health such as mortality, morbidity, infectious diseases, cancer, respiratory diseases, waterborne and airborne diseases, malnutrition, lower rate of growth in children, diarrhea, typhoid, occupational and vector borne diseases, etc. The "response" has been provided according to these (physical and epidemiological) indicators. As seen in HEADLAMP"

\footnotetext{
${ }^{7}$ Briggs. D, Corvalan. C, Nurminen. M. (1996). Linkage Methods for Environment and Health Analysis, WHO.

${ }^{8}$ Levrel. H. Kerbiriou. Christian, C. Denis, Weber. Jaques. (2009). OECD Pressure-State- Response Indicators for Managing Bio Diversity: A Realistic Perspective for a French Bio Sphere Reserve, Biodiversity and Conservation, Springer.

9 HEADLAMP is a joint collaboration of UNEP, WHO, USEPA initiated in 1993. Its aim had been to show a linkage between human health and environment. It focused on the health impacts due to environmental contamination. For Further Explanation see "Health and Environment Analysis for decision Making" by Corvalan. C, Kjellstrom. T, in "Linkage Methods for Environment and Health Analysis", Edited by Briggs. D, Corvalan. C, Nurminen. M. 1996, WHO.
} 
project, Millennium Development Goals, various international conventions which focused on to reduction of pollutants into the environment. These responses may prove useful in removing the physical and epidemiological impediments in health but the impact on mental aspect due to political turmoil may not overcome. These may prove viable in developed and conflict free countries, but may not bring the expected end results in conflict torn zone. Hence, the status of physical health may improve on one hand but Mental Health remains debilitated at the other.

Armed conflict is almost seen in every part of the world. It is "development in reverse" (collier et al, 2003) ${ }^{10}$. The cost of the conflict is paid by the civilians in many forms, directly or indirectly related to their health and well being. Gates, Hegre et,al; (2012) did a comparative study in Burundi and Burkina Faso to see the developmental consequences of armed conflict. It was seen that both the countries followed a same trajectory of development upto 1990. But, after the civil war in Burundi, it shows a steep decline in growth. It became main impediment in achieving the Millennium Development Goals. The country stands low in universal education, environmental sustainability, and higher in poverty and hunger, child mortality, child morbidity ${ }^{11}$. Thus armed conflict paves a substantial amount of negative impact on the health and well being of an individual, directly or indirectly.

Seeing the extent of influence of armed conflict in mental health, it becomes important to include the ignored aspects such as armed conflict and mental health in developmental frameworks. Since these frameworks form a base for developmental policies and programmes, it needs to be inclusive of all factors affecting the development. Neglecting these indicators will not result in inclusive policies. For example MDGs where there is no mention of mental health and armed conflict or for that matter the recent SDGs where the mental health has received a minimum significance.

\section{Armed Conflict and Mental Health}

War brings with it catastrophic effects on health and well being. Studies show that besides death, disability, hunger, lack of shelter and livelihood, it lays long term psychological impact on the civilians involved, thereby reducing capacity of human capital by decreasing their potential and increasing their ineffectiveness. Study by WHO (2001) reflects that $10 \%$ of the population exposed to trauma or war develops serious psychological problems and 10\% develop behavioral changes which affects their effectiveness ${ }^{12}$. Studies done by various researchers on the impact of war on the mental health in different war torn countries has been compiled in the work of Laxaminarayna and Murthy ${ }^{13}$. The studies reveal that the civilian population including children and youth witnessing the traumatic experiences suffer from

\footnotetext{
${ }^{10}$ Gates. Scott, Hegre. Havard, Nygard. Havard, Strand. Havard. (2012). Development Consequences of Armed Conflict, World Development. Accessed from http://www.sciencedirect.com/science/article/pii/s0305750x12001015.

11 ibid.

${ }^{12}$ Laxaminarayna, R. Murthy, S. (2006). Mental Health Consequences of War: A Brief Review of Research Findings, World Psychiatry.

13 ibid.
} 
multitude of psychological disorders, although in varying degrees. The common symptoms found were Depression, Anxiety, PTSD, Social Dysfunctioning etc. The children in Gaza during intifada were observed and found to have developed a high prevalence of nervousness, fears, restlessness, sleep disturbances, nocturnal enuresis, and other psychosomatic symptoms ${ }^{14}$.

The social support networks such as family, relatives, and neighborhood have been seen to play an important role in coping these problems, but are destroyed in armed conflict situations. This support network acts as a buffer to minimize the psychological tensions. Social support is being considered as an important link between the health and vulnerability. This view is substantiated by the Elbert, Schauer et al. (2009) who believe that conflict renders mental impairments and weakens the social support network. This argument is also supported by Barenbaum, Ruchkin et al. (2004) $)^{15}$.

"Resilience" is believed to help in overcoming the psychological distress. Factors such as socio cultural context, individual capacities, parental support, parental monitoring, family, and community support has proved to be the promotive and protective factors for building resilience. Good parental support and apt parental monitoring, community acceptance and support are believed to raise the self esteem among the victims and minimizing their psychological distress levels ${ }^{16}$. Since the armed conflict destroys such social support linkages, hence proves challenging to maintain good psychological well being. Prolonged armed conflict exposes people to death and loss, which in turn directly affect the mental health and psychosocial functioning. Besides direst exposure to trauma and weakening of psycho social networks, the "daily stressors" have been considered to play a profound role in mental health (Andrew Rasmussen, Kenneth Miller, 2009).

\section{Armed Conflict and Mental Health Scenario in Kashmir}

Kashmir has been engaged in armed conflict since decades now. The Indian state has been engaged in perpetual violation of human rights in Kashmir. Deaths, Enforced Disappearances, torture, custodial killings, arbitrary detentions, rape and harassment, etc has been a regular phenomenon in Kashmir by the hands of Indian army. About 8000 persons have been subjected to involuntary disappearance, more than 70000 persons have been killed, and more than 6000 have been buried in unmarked mass graves ${ }^{17}$. The worst lot affected is children, because of being both active and passive participants. About 97000 to 100000 children have become orphans. The number of widows increased drastically from 16000 in 2000 to 32400 in 2008 (Dabla) ${ }^{18}$. Being the witness and survivors of such grave violations, this has

\footnotetext{
${ }^{14}$ Hein, Quota, Thabet, Sarraj. (1993). Trauma and Mental Health of Children in Gaza, British Medical Journal, Accessed from https://www.ncbi.nlm.nih.gov/pmc/articles/PMC1677511/pdf/bmj00017-0056d.pdf.

15 "Sustainable Development Starts with Safe, Healthy and Well Educated Children". (2013). Report prepared by UNICEF.

${ }^{16}$ See Tol. Wietse. A, Song. S. and Jordans, M. J. D. (2013). Annual Research Review: Resilience and mental health in children and adolescents living in areas of armed conflict - a systematic review of findings in low- and middle-income countries, Journal of child psychology and psychiatry.

${ }^{17}$ Alleged Perpetrators. (2012). Report prepared by JKCCS. 18 
profoundly affected the mental health of the people in Kashmir.

Living in vicious circle of violations of human rights and atrocities, the mental health patients have increased to an alarming extent in Kashmir. Every household in Kashmir has been a witness to atrocities and violations. As a result, the rush of psychiatric patients to lone mental hospital in Srinagar had increased from 6 per day in 1990 to 250-300 in 2000 per day. The total number of patients rose from 1760 in 1990 to 18000 in 1994, to over 50000 in 2003. In 2006 , the number of patients had increased to $82000^{19}$. According to the recent research report by the MSF, it was revealed that about $45 \%$ of the adults in kashimiri have symptoms of mental distress. About $41 \%$ in the valley are living with depression, with $10 \%$ having the severe depression. Almost 26\% population in the valley has Anxiety related disorders. About $19 \%$ of population is living with PTSD $^{20}$.

Various studies conducted by organizations and independent researchers had reflected the scenario of mental health in Kashmir. Exposure to traumatic events leads a profound impact on the emotional, behavioral, cognitive and physiological functioning of an individual. In a study "characteristics of depression in Kashmir" Amin and Khan (2009) reveals that the prevalence rate of depression is almost $55.72 \%$, particularly in the age group of 15 to 25 years of age followed by 26 to 35 years. However, a difference is seen in the prevalence rate according to gender, age and location. The women are believed to suffer from depression more $(60 \%)$ as compared to men $(51 \%)$. Women suffered from higher prevalence of depression in all the age groups, particularly among 26 to 35 years, the productive years of her life.

Besides depression, PTSD has been found common in kashimiri population with co-morbid psychiatric symptom of depression ${ }^{21}$. A hospital based study conducted by Margoob et al revealed an increasing trend in depressive disorders in Kashmir (1971: 16\%, 1980: 14\% and in 1989: 32\%). The armed conflict has been attributed as a cause to this dramatic rise in mental health problems. This has not only affected the individual alone, but has lingered the social and community support ${ }^{22}$. In addition to this, substance misuse and suicide among youth are on the rise ${ }^{23}$. The sphere of psychiatric morbidity is very high. About $25 \%$ of people in Kashmir are suffered from life time depressive disorders (Dr. Arshid) ${ }^{24}$. Measuring

http://www.hindustantimes.com/india/survey-on-orphans-and-widows-in-kashmir/story-U5hwCkEDQz5gBmrrk 7AYvJ.html.

19 Rather, Farooq. (2013). Armed Conflict in J\& K and its Impact on Society: A case study of Kashmir valley, International Journal of Scientific and Research Publications, 3 (2).

20 "Kashmir mental health survey-2015". A Report Prepared by MSF.

${ }^{21}$ Wani. Z.A, Margoob. M.A. (2006). Family Study of Adult PTSD Patients in South Asia: Experiences from Kashmir. JK-Practitioner. pp 61-64.

22 Margoob. M.A, Beg. A.A, Dutta. K, S. (1993). Depressive Disorders in Kashmir; A Changing SocioDemographic and Clinical Profile of Patients over the Past Two Decades. JK Practitioner, pp 22-24.

23 Amin. Syed, Khan. A. W. (2009). Life in Conflict: Characteristics of Depression in Kashmir, Accessed from www.ncbi.nlm.nih.gov/pmc/articles/PMC3068807/.

24 Yaswi, A., \& Haque, A. (2008). Prevalence of PTSD symptoms and depression and level of coping among the victims of the Kashmir conflict. Journal of Loss and Trauma, 13(5), pp 471-480. 
the variables like neuroticism, anxiety, guilt proneness, self control among the youth in Kashmir, shows increase in level among the youth who had been exposed to violent episodes as compared to non exposed group (Zoya, Yasir, Babita, 2016). In a study (Syed Shehna, Chandra Shekhar, undated) the authors attempted to compare the children of Kashmir and Jammu related to their emotional regulation. A significant difference has been found in emotional regulation and impact events scale between the kashimiri children and children of Jammu.

Not only the people who have been exposed directly suffered, but the indirectly affected group also shows the symptoms of depression. A study by Asima and Aneesa shows that $41 \%$ of the respondents were suffering from mental health problems. This group constitutes mothers who got their sons killed in the conflict (Asima Hassan, Aneesa Shafi, 2013). Various other psychological problems such as sleeping disturbances, nightmares, loss of interest in life, aggressive behavior had been found among the respondents. About $90 \%$ of the respondents had been found fearful and uncertain of coming back home after they left home for work or any other purposes. Psychiatric problems had affected the general health of the patients as well. Problems like hypertension, gastroenterological problems, cardiac problems, eating disorders, headache, general weakness had been found ${ }^{25}$.

"Daily stressors" precipitates the issues of mental illness. As a result, the children and youth develop revolutionary mindset. The children cannot afford to come out of this mental trauma in persistent conflict situations. Encountering the traumatic situations again and again solidifies their issues. They develop high levels of anxiety, fear, frustration. The height of radicalization can be analysed from the words of detained boy:

"Now I will not pelt stones, I want to wear an explosive laden jacket and blow myself up "26

The nourishment in this kind of environment has lead the psycho social development in such a way that children and youth tend to think on the revolutionary lines. For example, in a case where a child was detained under JKPSA (Jammu Kashmir Public Safety Act), his brother resorted to pelt stones. With no rehabilitative programme in place, more and more youth and children tend to develop the feeling of hatred, anger, resentment and revenge.

These children and youth tend to develop away from the prescribed norms of psycho social development of conflict free society. Their thinking and psychology is totally different from the children living in conflict free society. They tend to show a deviance from expected behavior. According to psychologist Dr. Mudasir Firdousi, says that children of such age should be engaged in education and skill development. But unfortunately, during this productive phase of their life they are arrested, which turns them into activists. They tend to develop revolutionary inclinations.

\section{Excerpts of the Interview}

\footnotetext{
${ }^{25}$ Hassan, A., \& Shafi, A. (2013). Impact of conflict situation on mental health in Srinagar, Kashmir. desh S, 1819(1), pg 101.

26 Dilnaz Boga, No Juvenile Court in J\&K, 2014, accessed from http://infochangeindia.org/children/features/no-juvenile-courts-in-jak/.
} 
In an interview with Zahraan (name Changed) who is a class $12^{\text {th }}$ student has developed a revolutionary psychology. Normally, the children of his age are expected to be concerned about his studies and his future prospects at this stage of development, shows a variance. In his words,

"We do want to study and be successful in our lives, but not the cost of our honour, respect, dignity and freedom. Living in an environment of armed conflict, education etc no more becomes a priority for you. The only priority becomes survival. Hence we resist for existence. We feel repulsive to any kind of development. Any developmental programme is rejected until this armed conflict comes to an end". ${ }^{27}$

In the words of Ahmed (name changed), who is class $10^{\text {th }}$ student. For him development is no more a priority. Living amid conflict has changed his priorities. He feels repulsive and indifferent towards the developmental projects and policies.

"We do not need any developmental project until the conflict is resolved. As long as conflict prevails, no developmental project is accepted. How can one think of development when he is deprived of relief of soul and mind and freedom of his choice. The real development is to have a sakoon (relief) of heart". ${ }^{28}$

In such situations, it becomes difficult to sustain development. With such grave situation of mental health in Kashmir, the response of the stakeholders has been inadequate. The government has provided a single Psychiatric hospital with disproportionate staff strength catering services to Kashmir, Ladakh and even areas of Banihal and Kishtiwar. The Mental Health Act is only on paper. No inclusive policy for mental illness had been developed. No doubt, the medicines are distributed free of cost at the hospital but the medicines are not always available. With growing poverty, the patients are not able to buy the medicines. This develops a relapse in illness.

Hafiza bano, 52 year old lady is suffering from "severe reactive depression". She had developed mental illness after his son was picked up by troops from his home. Belonging to a poor class family, now hafiza has stopped to take medicines, because the family could not afford to buy the anti depressants for her ${ }^{29}$.

\section{Importance of Mental Health and How Its Neglect Hinders Development}

In context of conflict hit Kashmir, people are very vulnerable to mental illness. Mental illness reduces the will, skillfulness, intellect, and potential to contribute to positive development. Mental illness does not affect individual alone, but impacts families, communities and societies at large. So, maintaining the lower level of mental health will imprint its repercussions on the family, community development and broadly impede societal development.

\footnotetext{
27 This information has been collected through personal interview with the respondent.

28 Information gathered through interview with the respondent.

29 Baba, Tamim. kashmir's mental health crisis. Accessed from http://www.aljazeera.com/indepth/features/2016/06/kashmir-mental-health-crisis-160620085520339.html.
} 
Since, health has been considered as an important indicator of development. Health is not been defined alone as freedom from physical disease and pain, but the inclusion of social well being as well (Philip. R. Lee, undated). Well being can be categorized into two aspects: objective well being and subjective well being. Objective well being is based on observable factors such as richness, health, tangible goods, etc and subjective well being is referred to well being which is experienced psychologically. Based on this typology, various indexes have been propounded which collectively determine the progress and development such as Human Development Index, Genuine Progress Indicator, Index of Sustainable welfare, Gross National happiness, Quality of Life Index ${ }^{30}$. Psychological wellbeing receives an important place in development.

Mental Health has been defined as the state of emotional wellbeing which prompts an individual to recognize their skills, to effectively deal with stressful life situations, to work to produce results and to contribute to society in which they live $\mathrm{e}^{31}$. Mental health disability incurs huge losses on the development, economically and socially. For example, People with mental health illness have lower rate of employability because of the reasons of absenteeism and early dropout rates. This adds loss to the global economy. As estimated loss of \$16tr has been recorded due to decreased productivities (World Economic Forum, 2011) ${ }^{32}$. Similarly, the society with mentally disturbed people cannot be considered a healthy society. With debilitated mental health, people feel repulsive and indifferent to other material and objective well being. Neglecting mental health development will ultimately put its impact on overall measure of development. Neglecting mental health will not allow achieving expected outcome in social development or simply impeding mental health will impede social development. Development in real terms put humans at its centre. It demands to have physical as well as mental needs and resources fulfilled. Overlooking the mental aspect in development will no longer help it to sustain. The sustainability of development therefore lies in taking simultaneously both the physical and mental health into consideration.

\section{Conclusion}

It is clear that health has received a fine position as an indicator of Sustainable Development. But the frameworks of Sustainable Development neglect certain important indicators. These frameworks focus only on physical and epidemiological factors which impacts the health of an individual. But, these frameworks can be found insufficient in particular situations [such as political turmoil/armed conflict]. Since, these frameworks form a base for developmental policies, it may not likely to bring the development in holistic sense because of negligence of certain important factors. The developmental policy based on these frameworks is more technical in nature, appropriate to remove the physical and epidemiological impediments in health but insufficient to find compatibility in political turmoil/Armed conflict. As shown, political turmoil contribute to ill mental health to a considerable level, is not being considered

\footnotetext{
${ }^{30}$ D’ Acci. Luca. (2011). Measuring well being and progress. Social Indicators Research, Springer.

31 See chapter "Promoting Mental Health: From Theory to Best Practice by Stelios Styliandias et al in book "Social and Community Psychiatry", pp 117-131.

32 ibid.
} 


\section{Macrothink}

in Sustainable Development Frameworks. No doubt, these frameworks will bring positive results in conflict free societies, but may not find much validity in armed conflict contexts. The proposed frameworks makes us to remain clinged to ameliorate physical and epidemiological factors affecting health, neglecting the mental health arising out of conflict, which should not be the case. Like the physical health, mental health is equally important in maintaining well being. Hence, the need is to develop a framework which takes into account the ignored aspects such as armed conflict and mental health. This paper shows a relationship among the variables, armed conflict and mental health in sustaining development and need to build the frameworks in a more holistic way.

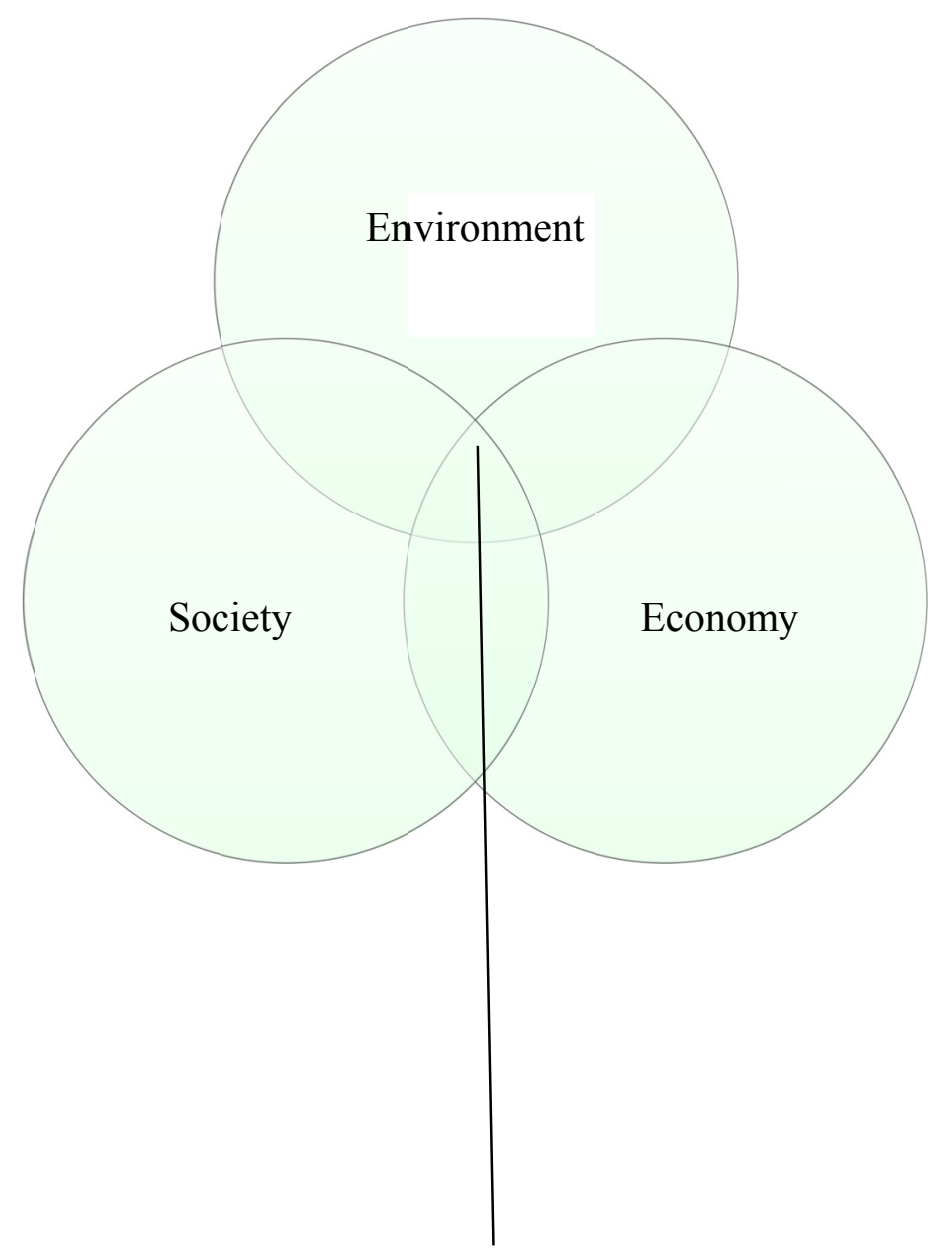

Fig 1. Sustainable Development

\section{References}

"Alleged Perpetrators", A Report Prepared by JKCCS.

Adshead, F., Thorpe, A., \& Rutter, J. (2006). Sustainable Development and Public Health: A National Perspective. The Royal Institute of Public Health. https://doi.org/10.1016/j.puhe.2006.10.003

Amin, S., \& Khan, A. W. (2009). Life in Conflict: Characteristics of Depression in Kashmir. 
Bannon, I., \& Collier, P. (2003). Natural resources and violent conflict. The World Bank. https://doi.org/10.1596/0-8213-5503-1

Bossel, H. (1999). Indicators for Sustainable Development: Theory, Method, Applications. International Institute for Sustainable Development, Canada.

Briggs, D., Corvalan, C., \& Nurminen, M. (1996). Linkage Methods for Environment and Health Analysis. WHO.

Corvalán, F. C., Kjellström, T., \& Smith, K. (1999). Health, Environment and Sustainable Development: Identifying Links and Indicators to Promote Action. Epidemiology Resource Inc. https://doi.org/10.1097/00001648-199909000-00036

D’ Acci, L. (2011). Measuring well being and progress. Social Indicators Research, Springer. https://doi.org/10.1007/s11205-010-9717-1

Dale, A., \& Newman, L. (2008). Social Capital: A Necessary and Sufficient Condition for Sustainable Community Development. Oxford University Press and Community Development Journal.

Dolan, P., Knight, M., Metcalfe, R., Peasgood, P., \& White, M. (n.d.). The relationship between well-being and Sustainable Development.

Gates, S., Hegre, H., Nygard, H., \& Strand, H. (2012). Development Consequences of Armed Conflict, World Development. https://doi.org/10.1016/j.worlddev.2012.04.031

Haines, A., Kovats, R. S., Lendrum, C., \& Corvalan, C. (2006). Climate Change and Human Health: Impacts, Vulnerability and Public Health. Journal of the Royal Institute of Public Health. https://doi.org/10.1016/j.puhe.2006.01.002

Harris, M. J. (2000). Basic Principles of Sustainable Development, Global Development and Environment Institute, Tufts University.(working paper series).

Hein, Q., \& Thabet, S. (1993). Trauma and Mental Health of Children in Gaza. British Medical Journal. https://doi.org/10.1136/bmj.306.6885.1130-c

Ivković, F. A., Ham, M., \& Mijoč, J. (2014). Measuring objective well being and Sustainable Development Management. Journal of Knowledge Management, Economics and Information Technology.

Jaipal, R. (2014). Psychological contributions to Sustainable Development. American psychological Associaltion.

Kashmir Mental Health Survey-2015. A Report Prepared by MSF.

Laxaminarayna, R., \& Murthy, S. (2006). Mental Health Consequences of War: A Brief Review of Research Findings. World Psychiatry

Levrel, H., Kerbiriou, C., Couvet, D., \& Weber, J. (2009). OECD Pressure-State- Response Indicators for Managing Bio Diversity: A Realistic Perspective for a French Bio Sphere Reserve, Biodiversity and Conservation, Springer. 
Margoob, M. A., Beg, A. A., \& Dutta, K. S. (1993). Depressive Disorders in Kashmir; A Changing Socio Demographic and Clinical Profile of Patients over the Past Two Decades. JK Practitioner.

Martens, W. J. M., Slooff, R., \& Jackson, E. K. (1997). Climate Change, Human Health and Sustainable Development. Bulletin of World Health Organisation.

Mitchel, G., May, A., \& McDonald, A. (1995). PICABUE: a methodological framework for the development of indicators of Sustainable Development. International Journal of Sustainable Development. https://doi.org/10.1080/13504509509469893

Parris, M. T., \& Kates, W. R. (2003). Characterizing and measuring Sustainable Development. Annual Review of Environment and Resources. https://doi.org/10.1146/annurev.energy.28.050302.105551

Rather, F. (2013). Armed Conflict in J\& K and its Impact on Society: A case study of Kashmir valley. International Journal of Scientific and Research Publications.

Review of the Sustainable Development Goals: The Science Perspective. Report published by International Council for Science. (2015).

Robert, W. K., Parris, M. T., \& Leiserowitz, A. (2012). What is Sustainable Development: Goals, Indicators, Values and Practice. Taylor and Francis Group.

Schirnding von, Y. (2002). Health and Environment Indicators in the context of Sustainable Development. Canadian Journal of Public Health.

Thornicroft, G., \& Patel, V. (2014). Including mental health among the new Sustainable Development goals, BMJ. https://doi.org/10.1136/bmj.g5189

Towards integration at last? The Sustainable Development goals as a network of targets, working paper series. (2015). DESA

Transforming our World: The 2030 Agenda for Sustainable Development, Document of united nations. (2015).

Votruba, N., Eaton, J., Prince, M., \& Thornicrof, G. (2014). The importance of global mental health for the Sustainable Development Goals. Journal of mental health. https://doi.org/10.3109/09638237.2014.976857

Wani, Z. A., \& Margoob, M. A. (2006). Family Study of Adult PTSD Patients in South Asia: Experiences from Kashmir. JK-Practitioner.

Yaswi, A., \& Haque, A. (2008). Prevalence of PTSD symptoms and depression and level of coping among the victims of the Kashmir conflict. Journal of Loss and Trauma. https://doi.org/10.1080/15325020802171441 


\section{Copyright Disclaimer}

Copyright reserved by the author(s).

This article is an open-access article distributed under the terms and conditions of the Creative Commons Attribution license (http://creativecommons.org/licenses/by/3.0/). 